\title{
Empresas sociais e sociedades comerciais: ¿realidades convergentes ou divergentes?
}

Social enterprises and commercial companies: converging or diverging realities?

Empresas sociales y sociedades comerciales: ¿realidades convergentes o divergentes?

\section{Deolinda Meira* Maria Elisabete Ramo**}

Recibido: 11 de julio de 2018 Aceptado: 20 de septiembre de 2018

Publicado: 5 de abril de 2019

Cómo citar este artículo: Meira, D. e Ramos, M. E. (2019). Empresas sociais e sociedades comerciais: realidades convergentes o divergentes. Cooperativismo \& Desarrollo, 27(1), 1-33. doi: https://doi.org/10.16925/2382-4220.2019.01.04

Artículo de investigación. https://doi.org/10.16925/2382-4220.2019.01.04

* Politécnico do Instituto Superior de Contabilidade e Administração do Porto (Portugal). Orcid: http://orcid.org/0000-0002-2301-4881. E-mail: meira@iscap.ipp.pt.

** Universidade de Coimbra (Portugal). Orcid: http://orcid.org/0000-0001-5376-4897.E-mail: mgramos@fe.uc.pt. 


\title{
Resumo
}

O presente artigo trata a relação entre as sociedades comerciais e as empresas sociais. Em primeiro lugar, identifica e analisa as iniciativas adotadas pelas instituições da União Europeia em matéria de empresas sociais. Em seguida, aborda soluções legislativas aplicadas por vários Estados-Membros. Por fim, reflete sobre o ordenamento jurídico português. Apesar de a União Europeia contar com várias iniciativas dirigidas às empresas sociais, esta é uma matéria não harmonizada. Neste contexto, vários Estados-Membros incorporam nos seus ordenamentos legislação específica sobre empresas sociais, mas são diferentes os modelos de legislação seguidos, bem como a regulação jurídica adotada. Das várias iniciativas da União Europeia sobre empresas sociais, é possível retirar três conclusões: as sociedades podem, cumpridos certos requisitos, ser consideradas empresas sociais; a ordem jurídica portuguesa não regula expressa e genericamente as empresas sociais; e a criação de figuras híbridas destinadas a acomodar as particularidades das empresas sociais depende da intervenção do legislador português.

Palavras-chave: empresa social, Lei de Bases portuguesa, economia social, sociedades comerciais.

\begin{abstract}
This paper discusses the relationship between commercial companies and social enterprises. First, this article identifies and analyses the initiatives taken by the European Union institutions in the field of social enterprises; secondly, it discusses legislative solutions adopted by several Member States; and, finally, it reflects on the Portuguese legal system. Although the European Union has several initiatives aimed at social enterprises, this is a non-harmonized matter. In this context, a number of Member States incorporated specific legislation on social enterprises into their legal systems, but the models of legislation differ, as well as the legal regulation adopted. From the various initiatives of the European Union on social enterprises, it is possible to draw three conclusions: companies can, if certain requirements are met, be considered as social enterprises; the Portuguese legal system does not, expressly and generically, regulate social enterprises; and the creation of hybrid figures designed to accommodate the specific characteristics of social enterprises depends on the Portuguese legislator intervention.
\end{abstract}

Key words: social enterprise, Lei de Bases portuguesa, social economy, commercial companies.

\section{Resumen}

El presente artículo trata la relación entre las sociedades comerciales y las empresas sociales. En primer lugar, identifica y analiza las iniciativas adoptadas por las instituciones de la Unión Europea en materia de empresas sociales. Luego, aborda las soluciones legislativas acogidas por varios Estados-miembros. Por último, examina el ordenamiento jurídico portugués. A pesar de que la Unión Europea cuenta con varias iniciativas dirigidas a las empresas sociales, este es un tema no armonizado. En este contexto, varios Estados-miembros incorporaron legislación específica sobre empresas sociales en sus ordenamientos, pero los modelos de legislación son distintos, así como la regulación jurídica adoptada. De las varias iniciativas de la Unión Europea sobre empresas sociales, es posible concluir tres aspectos: las sociedades, al cumplir ciertos requisitos, pueden ser consideradas empresas sociales; el ordenamiento jurídico portugués no regula las empresas sociales de forma expresa ni genérica; y la creación de figuras híbridas destinadas a acomodar las particularidades de las empresas sociales depende de la intervención del legislador portugués. 


\section{Introdução}

Em Portugal, a Lei de Bases da Economia Social n. ${ }^{\circ}$ 30/2013 de 8 de maio (LBES) delimita o conceito de Economia Social socorrendo-se de dois critérios: um critério objetivo (que se reporta à atividade desenvolvida e ao fim prosseguido) e um critério subjetivo (centrado na forma jurídica da entidade). A Economia Social é definida como o conjunto das atividades económico-sociais livremente levadas a cabo pelas entidades referidas no artigo $4 .^{\circ}$ da lei mencionada.

Esta disposição legal apresenta uma cláusula aberta em que integra na Economia Social, para além das famílias tradicionais (cooperativas, mutualidades, associações e fundações), outras entidades dotadas de personalidade jurídica, que respeitem os princípios orientadores da Economia Social e que constem sua base de dados. Neste contexto, este estudo pretende responder às seguintes questões:

1. Prevê a LBES o conceito de empresa social?

2. É clara a LBES na aceitação de uma sociedade comercial como empresa social?

3. Abrangerá o art. $4 .{ }^{\circ}$, al. h) da LBES as sociedades comerciais como empresas sociais?

4. Existirá no ordenamento português legislação especialmente dedicada a regular as empresas sociais?

5. Que impactos tem a não harmonização europeia da legislação sobre empresa social no ordenamento português, no qual se assiste um debate em torno do conceito de empresa social?

A resposta a estas questões exige considerar a referida cláusula do art. $4 .^{\circ}$ da LBES; o conceito de empresa social, constante quer de vários documentos das instituições da União Europeia, quer das definições legais e doutrinais existentes na Europa aspetos específicos do regime português das sociedades comerciais e as soluções legais consagradas em outros ordenamentos europeus.

Este estudo centra-se no contexto da União Europeia, dado que se considera que este referente poderá ter algum impacto na legislação portuguesa. Acresce o facto de, na Europa, o conceito de empresa social ter sido desenhado em diálogo com o conceito já consolidado de Economia Social. 


\title{
A não harmonização do regime jurídico das empresas sociais na União Europeia
}

\author{
O Comité Económico e Social Europeu (2017) salienta que:
}

Entre 2009 e 2017, as instituições europeias realizaram várias iniciativas relativas à Economia Social, ou mais exatamente a favor das empresas sociais que dela fazem parte, dando início a um novo período das políticas públicas europeias. Quanto às formas jurídicas, registaram-se poucos progressos. Os projetos de estatuto da sociedade mútua europeia e o Estatuto da Fundação Europeia (FE) foram debatidos, mas acabaram por ser retirados devido à falta de apoio institucional. Atualmente, o Parlamento Europeu tomou a iniciativa legislativa de trabalhar num estatuto para as empresas sociais e solidárias. (p. 18)

No contexto da União Europeia, a disciplina jurídica em matéria de empresas sociais é uma regulação de fonte nacional e não harmonizada. O mesmo acontece com o direito cooperativo que é, essencialmente, um direito de fonte principalmente nacional (Meira e Ramos, 2014). O Estatuto da Sociedade Cooperativa Europeia (ESCE) não contradiz esta afırmação, porquanto o propósito do regulamento que cria esta figura não é o de harmonizar ou uniformizar o direito cooperativo na União Europeia, mas tão só o de criar um "estatuto jurídico europeu para as cooperativas, baseado em princípios comuns" (Ponto 12 do Preâmbulo do ESCE).

Considera-se que a criação de regimes comuns tem de resultar de novas abordagens. Em vários domínios, e não só no das cooperativas, assiste-se a projetos de iniciativa académica destinados a identificar e elaborar os princípios comuns no espaço europeu. No contexto das cooperativas, destacam-se os Princípios do Direito Cooperativo Europeu (Projeto PECOL: Principles of European Cooperative Law), que são um conjunto de normas que se apresentam como "ideais" na regulação das cooperativas europeias e que refletem os seus traços mais caraterísticos. Estas normas foram elaboradas por um grupo de docentes e investigadores especialistas em direito cooperativo (SGECOL - Study Group on European Cooperative Law), depois de uma investigação comparada da legislação cooperativa e das melhores práticas em sete ordenamentos europeus (Alemanha, Espanha, Finlândia, França, Itália, Portugal e Reino Unido) (Fajardo et al., 2013).

1 Regulamento (CE) n. ${ }^{\circ} 1$ 435/2003, do Conselho, de 22 de julho de 2003, relativo ao Estatuto da Sociedade Cooperativa Europeia (ESCE). 
O PECOL não tem como objetivo específico o de promover a harmonização das legislações nacionais sobre cooperativas, mas aspira a que estes princípios possam ser reconhecidos e assumidos pelas organizações cooperativas e possam constituir uma referência para o legislador aquando da regulação jurídica das cooperativas (Fajardo et al., 2017).

Esta não harmonização não obsta a que a União Europeia, através de iniciativas da Comissão Europeia e do Parlamento Europeu, reconheça o relevo económico e social da Economia Social e tenha desenvolvido, na evolução recente, vários documentos destinados a refletir sobre a Economia Social e as empresas sociais.

Segundo a Carta dos Princípios da Economia Social, elaborada pela Social Economy Europe ${ }^{2}$, a Economia Social rege-se pelos seguintes princípios: primazia do indivíduo e do objetivo social sobre o capital; adesão livre e voluntária; controle democrático pelos seus filiados (exceto as fundações, que não possuem membros associados); conjugação dos interesses dos filiados ou utilizadores com o interesse geral; defesa e aplicação dos princípios de solidariedade e responsabilidade; autonomia de gestão e independência em relação aos poderes públicos; afetação da maior parte dos excedentes à consecução dos objetivos de desenvolvimento sustentável e à prestação de serviços de interesse para os filiados ou de interesse geral.

Assim, no espaço da União Europeia convivem as caraterizações da Economia Social, desenvolvidas por instâncias europeias com as definições, muitas vezes legais, vigentes nos regimes jurídicos nacionais. É o que acontece no caso português, com a Lei de Bases da Economia Social, como será exposto mais adiante.

2 Déclaration finale commune des organisations européennes de l'Économie Sociale, CEP-CMAF, 20 de junho de 2002. 


\section{Comunicação da Comissão Europeia - "Iniciativa de empreendedorismo social. Construir um ecossistema para promover as empresas sociais no centro da economia e da inovação sociais" [SEC (2011) 1278 final]}

Nesta comunicação ${ }^{3}$, a Comissão Europeia considera que a empresa social integra a Economia Social. Assim, para a Comissão Europeia,

[] uma empresa social, agente da Economia Social, é uma empresa cujo objetivo principal é ter uma incidência social, mais do que gerar lucros para os seus proprietários ou parceiros. Opera no mercado fornecendo bens e prestando serviços de maneira empresarial e inovadora, e utiliza os seus excedentes principalmente para fins sociais. É gerida de forma responsável e transparente, nomeadamente associando os seus empregados, os seus clientes e outras partes interessadas (p.2).

A Comissão, por "empresa social", entende as empresas:

- Cujo objetivo social ou de sociedade, de interesse comum, justifica a ação comercial, que se traduz, frequentemente, num alto nível de inovação social.

- Cujos lucros são reinvestidos principalmente na realização desse objeto social.

- Cujo modo de organização ou sistema de propriedade reflete a sua missão, baseando-se em princípios democráticos ou participativos ou visando a justiça social.

É claro que a Comissão Europeia não usa a forma jurídica como critério de delimitação da empresa social. Esta comunicação admite, aliás, que entidades lucrativas, máxime sociedades, possam ser consideradas empresas sociais, desde que cumpram os requisitos elencados pela Comissão Europeia.

3 Trata-se da Comunicação da Comissão ao Parlamento Europeu ao Conselho, ao Comité Económico e Social Europeu e ao Comité das Regiões, Iniciativa de Empreendedorismo Social. Construir um ecossistema para promover as empresas sociais no centro da economia e da inovação sociais, SEC (2011) 1278 final. 
O interesse em torno das empresas sociais não é só académico ou conceitual. Na verdade, a Comissão Europeia considera que as empresas sociais necessitam de ser apoiadas (talvez porque o Estado vai recuando no cumprimento da sua missão social). Para tanto, elege o acesso ao financiamento por parte das empresas sociais como um dos fatores estratégicos para o seu desenvolvimento. Neste contexto, pontua não só o acesso a financiamento privado, mas especialmente o acesso a auxílios públicos providenciados pelos Estados-membros e pelas regiões, no "Horizonte 2014-2020" (ponto 3.1.2. da Comunicação com [2011] 682).

A Comissão Europeia pretende criar condições para incentivar os Estadosmembros e as regiões a incluírem ações orientadas às empresas sociais nos seus programas do Fundo Social Europeu (FSE) e do Fundo Europeu de Desenvolvimento Regional (FEDER) para 2014-2020 (ponto 3.1.2. da Comunicação COM (2011) 682, ação-chave n. ${ }^{0}$ 4). E, desta forma, porque as empresas sociais são "elegíveis" para o acesso a auxílios públicos, elas tornam-se interessantes para os agentes económicos.

\section{Relatório do Grupo de Peritos da Comissão sobre o Empreendedorismo Social (GECES)}

Em outubro de 2016, o Grupo de Peritos da Comissão sobre o Empreendedorismo Social ${ }^{4}$ advoga:

[] um plano de ação europeu para a Economia Social e as empresas sociais, que daria um novo alento à promoção de um ambiente propício à prosperidade das empresas sociais e da Economia Social, inspirando-se nos seus valores fundamentais, tais como a governação democrática, o impacto social, a inovação, o reinvestimento dos lucros ou a atribuição de um lugar de destaque às pessoas na economia. Com esta capacitação, as empresas sociais e a Economia Social terão um impacto ainda mais significativo na resolução dos desafios acima destacados e ajudarão a criar uma sociedade mais equitativa em termos sociais na Europa. (C13/152).

4 Parecer exploratório do CESE sobre o tema "construir um ecossistema financeiro para as empresas sociais" (JO C 13 de 15.1.2016). 
Uma das recomendações do Grupo de Peritos versa, justamente, sobre as melhorias regulatórias que será necessário introduzir nas legislações nacionais, de modo a criar um ambiente legal propício ao desenvolvimento das empresas sociais, nomeadamente eliminando requisitos considerados obsoletos ou redundantes ${ }^{5}$. Assim, segundo este grupo de peritos,

[] para facilitar o desenvolvimento de um ecossistema no qual as empresas sociais possam prosperar, elaborou-se um conjunto de recomendações fundamentais sobre ambiente jurídico e a definição de quadros jurídicos e regulamentares para incentivar a criação e o desenvolvimento da Economia Social e das empresas sociais. Neste contexto, recomenda-se que a Comissão proponha um ato jurídico de caráter não vinculativo para ajudar os Estados Membros a conceberem um quadro adequado que vise apoiar a Economia Social e as empresas sociais (p. 4).

Neste contexto é formulada a recomendação 7 que apresenta o seguinte teor:

A Comissão deve propor um ato jurídico de caráter não vinculativo para ajudar os Estados-membros a conceberem um quadro adequado que vise ajudar as empresas a prosperarem e a expandirem-se. As ações devem incluir:

-A elaboração de uma recomendação jurídica, com base nos Tratados, que estabeleça princípios mínimos de incentivo e apoio aos Estados-membros na criação de um quadro nacional específico para o desenvolvimento das empresas sociais (Comissão);

-A monitorização das políticas das empresas sociais no âmbito do Semestre Europeu, a fim de acompanhar a aplicação da recomendação jurídica supra (Comissão) (p. 9).

Vê-se, pois, que o Grupo de Peritos, em sintonia com a posição defendida pela Comissão em 2011, não valoriza a forma jurídica das empresas sociais e, por esta via, admite que entidades lucrativas sejam, cumpridos certos requisitos, consideradas empresas sociais.

5 Comissão Europeia (2016). O futuro das empresas sociais e da economia social. Um apelo à ação do Grupo de Peritos da Comissão sobre o Empreendedorismo Social (GECES). Síntese e Recomendações. Bruxelas. 


\section{Projeto de Relatório do Parlamento Europeu de 23 de outubro de 2017, relativo a um estatuto para as empresas sociais e solidárias}

Em 23 de outubro de 2017, o Parlamento Europeu, através do Projeto de relatório que contém recomendações à Comissão sobre um estatuto para as empresas sociais e solidárias (2016/2237 [INL]), "insta à Comissão a introduzir, a nível da União, um 'rótulo social europeu' a atribuir às empresas sociais". O Parlamento Europeu considera que "as organizações que cumpram uma série de requisitos legais, independentemente da forma jurídica da sua constituição num Estado-membro, devem ter acesso ao rótulo social europeu" (Ponto X.1. do Projeto de Relatório do Parlamento Europeu).

Na sequência da sua resolução de 10 de setembro de 2015, em que o Parlamento observa que as empresas da Economia Social e solidária "não têm de ser necessariamente organizações sem fins lucrativos", em 2017 é reiterada esta opção. Assim, em 2017, o Parlamento Europeu considera que "as empresas sociais podem ter fins lucrativos". Acrescenta o Parlamento Europeu que, não obstante tal fim lucrativo, as

[] empresas sociais devem centrar-se principalmente nos valores sociais e no impacto positivo e duradouro que podem ter sobre o bem-estar da sociedade e o desenvolvimento económico, e não em gerar lucros para os seus proprietários, sócios ou acionistas; que, neste contexto, uma restrição à repartição de lucros e ativos entre sócios ou acionistas, também conhecida por "bloqueio de ativos" (asset lock), é essencial para as empresas sociais; que se pode permitir uma repartição limitada dos lucros, tendo em conta a forma jurídica adotada pela empresa social, mas que os procedimentos e as regras a plicáveis a essa repartição devem assegurar que a mesma não prejudique o objetivo principal da empresa; que a percentagem mais significativa dos lucros de uma empresa social deve ser reinvestida ou utilizada na realização do seu objetivo social. (Ponto Q. do Projeto de Relatório do Parlamento Europeu). 


\section{Breve caraterização das empresas sociais na legislação comparada}

Mais de 25 anos volvidos desde a aprovação da primeira lei sobre empresas sociais -a lei italiana n. ${ }^{0}$ 381/1991 sobre cooperativas sociais- assistiu-se ao longo deste período ao surgimento de legislação específica sobre esta temática quer nos Estados Unidos quer nos Estados-membros da União Europeia.

Nos Estados Unidos assistimos à proliferação de leis estatais destinadas à criação de formas jurídicas específicas para a empresa social, com destaque para as seguintes: Low-Profit Limited Liability Company (L3C), Public Benefit Coprporation (BCORP) e Social Purpose Corporation (SPC) (Murray, 2015).

$\mathrm{Na}$ União Europeia, encontram-se diversos modelos de legislação para a empresa social, sendo que a natureza jurídica desta dependerá do modelo adotado. Numa primeira vaga europeia de empresas sociais, destacam-se a cooperativa social italiana (Lei Italiana n. ${ }^{\circ}$ 381/91), as cooperativas de interesse coletivo do ordenamento francês (société coopérative d'intérêt collectif, Lei n. ${ }^{\circ}$ 2001/624, de 17 de julho de 2001, alterada pela Lei n. ${ }^{\circ} 2014 / 856$ de 31 de julho de 2014), as cooperativas de solidariedade social previstas no ordenamento português (Decreto-Lei n. ${ }^{\circ} 78 / 98$, de 15 de janeiro), as cooperativas de iniciativa social do ordenamento espanhol (Lei n. ${ }^{0}$ 27/1999, de 16 de julho) e a britânica community interest company (CIC), a sociedade de interesse comunitário, entre outras.

Numa segunda vaga europeia de empresas sociais, o termo "empresa social" identifica uma categoria específica de entidades, uma qualificação legal (ou status). Assim, este estatuto jurídico pode ser atribuído a entidades com formas jurídicas diversas (uma sociedade, uma cooperativa, uma associação, uma fundação, entre outras), desde que obedeçam a um conjunto de requisitos legais. Este é o modelo adotado na Itália, pelo Decreto Legislativo n. ${ }^{0}$ 155/2006 sobre impresa sociale, o qual amplia as formas jurídicas de empresa social relativamente à Lei n. ${ }^{\circ}$ 381/91 sobre cooperativas sociais. Este modelo está também presente em outros Estados-membros, tais como a Dinamarca (Lei n. ${ }^{\circ} 711$ de 25 de junho de 2014, sobre Empresas Sociais Registadas [registrerede socialøkonomiske virksomheder]); a Finlândia (Lei n. ${ }^{0}$ 1351/2003, de 30 de dezembro de 2003, sobre empresas sociais [sosiaalisista yrityksistä]) e a Roménia (artigos 8 e seguintes sobre a empresa social [întreprinderea socială] da Lei n. ${ }^{0} 219$ de 23 de julho de 2015 sobre Economia Social).

Outro critério importante de classificação é aquele que distingue entre as leis que reconhecem a empresa social apenas como de inserção pelo trabalho (WISE, na sigla inglesa), cujos objetivos consistem na criação de emprego e na integração 
de desempregados ou de trabalhadores com necessidades especiais no mercado de trabalho (como é o caso das empresas de inserção (Lei n. ${ }^{\circ}$ 44/2007 de 13 de dezembro) e dos centros especiais de emprego (Real Decreto Legislativo n. ${ }^{\circ}$ 1/2013 de 29 de novembro de 2013) do ordenamento espanhol; e leis segundo as quais o que identifica a empresa social é o desenvolvimento de várias atividades de utilidade social, incluindo, mas não se limitando à integração no mercado de trabalho de grupos desfavorecidos ou trabalhadores (como é o caso société à finalité sociale do ordenamento belga); da cooperativa social do ordenamento croata (socijalne zadruge); da cooperativa social da República Checa (sociální družstvo); da entreprise solidaire

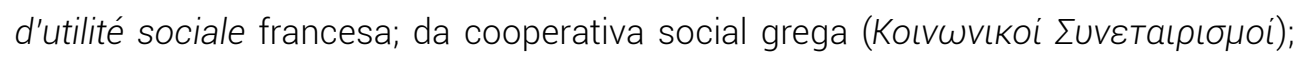
entre outras (Fici, 2016).

Uma das principais razões invocadas pela doutrina para o surgimento desta diversidade de regimes jurídicos sobre empresa social é o da inadequação do quadro legislativo em vigor para conferir uma adequada veste jurídica a fenómenos empreendedores e inovadores caraterizados pela prossecução, a título principal, de uma finalidade de interesse coletivo e pela ausência de um escopo lucrativo ou em que os lucros são principalmente reinvestidos no fim prosseguido, a que acresce um modo de organização baseado nos princípios democrático e participativo. Tal não significava que a legislação existente sobre associações, fundações, cooperativas, sociedades ou outras entidades não consentisse a constituição e a atividade de empresas sociais, mas que a mesma limitava ou obstaculizava a possibilidade de estas formas jurídicas desenvolverem uma atividade empresarial que visasse o interesse geral (Fici, 2017; Farinho, 2015).

No caso específico do direito e da legislação societária, que constitui o foco do presente estudo, invocava-se que os mesmos foram pensados para entidades caraterizadas por um escopo lucrativo ou de maximização dos valores dos sócios (shareholder value maximization), o que impediria a prossecução a título principal de um escopo diverso.

Sendo que as formas jurídicas puras do setor não lucrativo e as formas jurídicas puras do setor lucrativo se mostravam inadequadas para enquadrar estes fenómenos empresariais com finalidades de interesse geral, impunha-se a criação de uma forma jurídica específica que respondesse às exigências de uma entidade relativamente híbrida às tipologias preexistentes, que combinasse a atividade típica de um ente lucrativo com o escopo típico de um ente não lucrativo (Fici, 2017). 


\section{A proposta EMES - European Research Network e a admissão de sociedades como empresas sociais}

$\mathrm{Na}$ consolidação do conceito de empresa social, a nível europeu, destaca-se a proposta da European Research Network (EMES) ${ }^{6}$, que começa a ser construída nos anos noventa do século XX, e que vê as empresas sociais como modelos organizativos empreendedores e inovadores do ponto de vista social.

Segundo a EMES, são identificáveis três dimensões nas empresas sociais: a económica e empreendedora que se centra na atividade desenvolvida; a dimensão social que qualifica o objetivo prosseguido; e a dimensão participativa que carateriza a sua governação. Em cada uma destas dimensões identificam-se várias vertentes (Defourny e Nyssens, 2012).

Assim, tendo em conta a dimensão económica e empreendedora, uma empresa social deve ter: a) uma atividade continuada de produção de bens e de prestação de serviços, não se limitando a atividades de defesa de interesses, lobbying ou distribuição de recursos financeiros a partir de fundos privados ou fundações; b) um nível significativo de risco económico, fazendo depender a viabilidade financeira da capacidade dos seus membros e trabalhadores em assegurar os recursos adequados; $c$ ) um nível mínimo de trabalho remunerado, ainda que as atividades possam ser desenvolvidas com recursos monetários e não-monetários ou com trabalho voluntário.

Tendo em conta a dimensão social, uma empresa social deve preencher as seguintes condições: a) ter um objetivo específico em benefício da comunidade ou de um grupo determinado; b) ser criada voluntariamente por um grupo de cidadãos ou organizações da sociedade civil; e c) ter uma distribuição limitada de lucros, sendo dada prioridade à finalidade social.

Por último, em relação à governação, uma empresa social deve ter: a) um elevado grau de autonomia (é criada por um conjunto de pessoas e é governada com base num projeto autónomo); b) um poder de decisão não baseado na posse do capital, mas no princípio democrático assente na regra "um membro, um voto"; e c) uma natureza participativa que envolva as várias partes interessadas na atividade, em que se promova e fomente a representação e participação dos beneficiários, dos trabaIhadores e de outras partes interessadas na gestão e nos processos de decisão da organização (Defourny e Nyssens, 2012). Com base nestas dimensões, a EMEs define as empresas sociais como:

6 A EMES - European Research Network é uma rede de investigação patrocinada pela União Europeia cuja finalidade é construir, de forma gradual, um corpo europeu de conhecimento teórico e empírico relacionado com as questões do terceiro sector. Foi criada em 1996 por um grupo de académicos internacionais que atingiram um invulgar grau de comum entendimento, confiança e modo de trabalho. Ver www.emes.net. 
Organizações privadas, autónomas e empreendedoras que providenciam produtos ou serviços com o objetivo explícito de beneficiar à comunidade (...) detidas e geridas por um grupo de cidadãos, em que o interesse material dos investidores está sujeito a limites (...), estando ora proibidas legalmente de distribuir lucros ora estruturadas de forma a excluir o lucro como objetivo principal. (Borzaga, Galera e Nogales, 2008, p. 5)

Torna-se evidente à luz deste conceito que, para a EMES, as empresas sociais podem assumir, entre outras, a forma de sociedade comercial, tal como é entendida no ordenamento jurídico português.

\section{Sociedades e empresas sociais no direito português}

\section{A caraterização de Economia Social na Lei de Bases de Economia Social}

Na Lei n. ${ }^{\circ}$ 30/2013, de 8 de maio, Lei de Bases da Economia Social (LBES), o legislador delimita o conceito de Economia Social, recorrendo a uma técnica combinada, a qual complementa a definição de Economia Social constante do art. 2. ${ }^{\circ}$ por uma enumeração aberta das entidades da Economia Social (art. $4^{\circ}$ ) e por uma enunciação dos seus princípios orientadores (art. 5. ${ }^{\circ}$ ).

Assim, nos termos dos artigos n. 1 e $2 .^{\circ}$ da LBES, "entende-se por economia social o conjunto das atividades económico-sociais, livremente levadas a cabo por entidades referidas no art. 4. ${ }^{\circ}$ [...]", atividades estas que "têm por finalidade prosseguir o interesse geral da sociedade, quer diretamente quer através da prossecução dos interesses dos seus membros, utilizadores e beneficiários, quando socialmente relevantes".

Desta definição ressaltam dois critérios delimitadores do conceito de Economia Social: a atividade desenvolvida e o fim prosseguido. De facto, o legislador associa a noção de Economia Social a um objeto social específico, traduzido no exercício de uma atividade económico-social, a qual terá por finalidade a prossecução de um interesse geral.

O termo atividade económica significará, nas palavras de Namorado (2007), uma atividade de "produção de bens e serviços, sob a égide de uma racionalidade que implique a maximização dos resultados, a contenção dos custos e a reprodutibilidade 
das virtualidades produtivas" (pp. 10-11). Ter uma atividade económica é condição necessária para considerar que uma entidade integra o setor da Economia Social. Contudo, esta atividade não é apenas uma atividade económica, mas também uma atividade social. Estima-se que, com o estabelecimento desta ligação entre os termos "económico" e "social", através de um hífen, o legislador pretendeu destacar que a atividade desenvolvida pelas entidades da Economia Social não tem uma finalidade lucrativa, mas a finalidade de satisfazer as necessidades dos membros, mediante a participação destes na referida atividade (mutualidade), ou a satisfação das necessidades da comunidade.

Quanto ao critério da finalidade prosseguida -o interesse geral-, considera-se que este se prende não apenas com o facto de estas entidades prosseguirem fins sociais, surgindo como parceiros do estado social, cooperando com este na garantia de um mínimo vital de direitos económicos, sociais e culturais dos cidadãos, mas também com o seu peculiar modo de organização e funcionamento, distinto do setor público e do setor privado lucrativo e refletido nos seus princípios orientadores, de entre os quais se destaca a este propósito o da "conciliação entre o interesse dos membros, utilizadores ou beneficiários, e o interesse geral" (Meira, 2016, p. 186), como será apresentado. Ora, quanto à prossecução deste interesse geral, o legislador admite que pode ser direta ou indireta através dos interesses dos membros, utilizadores e beneficiários.

Como exemplo de entidades que prosseguem diretamente fins de interesse geral, aponte-se o das entidades com o estatuto de Instituições Particulares de Solidariedade Social (doravante IPSS), que enquadra pessoas coletivas, sem carácter lucrativo, tem como principal objetivo a solidariedade social, com uma clara missão de apoio a situações de vulnerabilidade económica e social, e se assenta num paradigma assistencialista de intervenção social (art. 1. ${ }^{\circ}$ do Decreto-Lei n. ${ }^{\circ}$ 119/83, de 25 de fevereiro, republicado pelo Decreto-Lei n. ${ }^{0}$ 172-A/2014, de 14 de novembro, e alterado pela Lei n. ${ }^{\circ}$ 76/2015, de 28 de julho) (Almeida, 2011).

Existem outras entidades onde a prossecução do interesse geral é indireta. É o caso das cooperativas - com exceção das cooperativas de solidariedade social- em cujo objeto social se articulam duas dimensões: a económica e a social. Efetivamente, as cooperativas são empresas que visam diretamente o exercício de uma atividade económica (art. $7 .^{\circ}$ do Código Cooperativo Português - ccoop ${ }^{7}$ ) que é desenvolvida no interesse dos seus membros, mas tendo sempre em vista a prossecução de objetivos sociais.

7 Lei n. ${ }^{\circ}$ 119/2015, de 31 de agosto, com as alterações constantes da Lei n. ${ }^{\circ}$ 66/2017, de 9 de agosto. 
De facto, o fenómeno cooperativo, desde sempre, combinou uma dimensão fortemente social com uma dimensão económica, traduzida esta na satisfação dos interesses económicos dos seus membros. Esta combinação resulta, desde logo, da própria noção de cooperativa constante do art. $2 .^{\circ}$ do Ccoop, nos termos do qual o objeto da cooperativa se traduz na satisfação, sem fins lucrativos, das necessidades económicas, sociais ou culturais dos seus membros, e do modo de gestão da empresa cooperativa que, nos termos daquela noção, assenta na obediência aos princípios cooperativos, e na cooperação e entreajuda dos membros.

A missão social das cooperativas resulta, sobretudo, desta obediência aos princípios cooperativos formulados em 1995 em Manchester, que constituem o aspeto da identidade cooperativa com reflexos jurídicos mais importantes e diretos, e de entre os quais se destaca a necessária convivência das dimensões económica e social nas cooperativas.

Efetivamente, as cooperativas prosseguem uma clara missão social, conjugando os interesses dos seus membros com o interesse geral e com a consequente prossecução de objetivos de desenvolvimento sustentável. Os fins e a função da cooperação não se circunscreverão aos seus membros, posto que devem atender, igualmente, os interesses da comunidade onde a cooperativa desenvolve a sua atividade.

Neste sentido, o princípio do interesse pela comunidade, que aparece enunciado no art. 3. ${ }^{\circ}$ do ccoop, dispõe que "as cooperativas trabalham para o desenvolvimento sustentável das suas comunidades, através de políticas aprovadas pelos membros", pelo que as cooperativas se assumem como organizações que, existindo para benefício dos seus membros, assumirão, concomitantemente, uma responsabilidade perante a comunidade em que se insiram, ou seja, assegurarão que se realizará o desenvolvimento sustentável dessas comunidades nas suas distintas facetas: económica, social e cultural (Meira, 2009).

A definição de Economia Social é complementada por uma enumeração aberta das suas entidades constante do art. $4 .{ }^{\circ}$, nos termos do qual:

(...) integram a Economia Social, nomeadamente, as seguintes entidades, desde que constituídas em território nacional: a) cooperativas; b) associações mutualistas; c) misericórdias; d) fundações; e) instituições particulares de solidariedade social não abrangidas pelas alíneas anteriores; f) associações com fins altruísticos que atuem no âmbito cultural, recreativo, do desporto e do desenvolvimento local; g) entidades abrangidas pelos subsetores comunitário e autogestionário, integrados nos termos da CRP no setor cooperativo e social; h) outras entidades dotadas de per- 
sonalidade jurídica que respeitem os princípios orientadores da Economia Social, previstos no art. 5. ${ }^{\circ}$ da LBES, e que constem da base de dados da Economia Social (Diário da República, I série, n. ${ }^{\circ} 88$, de 8 de maio de 2013, p. 2727).

Assim, à semelhança do legislador espanhol, a LBES não adota a forma jurídica das entidades como critério exclusivo de delimitação subjetiva. Efetivamente, o legislador, para além das formas jurídicas correspondente es à delimitação tradicional das famílias da Economia Social (cooperativas, mutualidades, associações e fundações), fala, igualmente, de um estatuto jurídico (o Estatuto das Instituições Particulares de Solidariedade Social - IPSS).

No presente artigo, considera-se acertada esta opção do legislador, pois não obstante as IPSS poderem revestir a forma de associações de solidariedade social, associações de voluntários de ação social, associações de socorros mútuos, fundações de solidariedade social e irmandades da misericórdia, tal estatuto também pode ser concedido por equiparação a cooperativas (Lei n. ${ }^{0}$ 101/97 de 13 de setembro e o Despacho n. ${ }^{\circ}$ 3859/2016, de 16 de março) a Casas do Povo (Decreto-Lei n. ${ }^{\circ}$ 171/98 de 25 de junho e o Despacho n. ${ }^{0} 17747 / 99$ de 10 de setembro ${ }^{8}$ ) ou a outras entidades não abrangidas pelas famílias tradicionais da Economia Social.

$\mathrm{Na}$ al. d) desta norma, o legislador destacou, dadas as suas especificidades, as misericórdias, que são associações que integram a ordem jurídica canónica e que visam -enquadradas pelos princípios da doutrina e a moral cristãs- satisfazer carências sociais e praticar atos de culto católico, tendo, na ordem jurídica civil, a natureza de instituições particulares de solidariedade social (art. 68. ${ }^{\circ}$ do DecretoLei n. ${ }^{\circ}$ 119/83, de 25 de fevereiro). Neste âmbito legal, a esta família da Economia Social pertencem todas as Santas Casas da Misericórdia, as Irmandades das Santas Casas das Misericórdias e Misericórdias existentes em Portugal, com exceção da Santa Casa da Misericórdia de Lisboa que é uma pessoa coletiva de utilidade pública administrativa, estando integrada no setor da Administração Pública.

8 Nos termos dos artigos. $1 .^{\circ}$ e $2 .^{\circ}$ do Decreto-lei n. ${ }^{\circ} 4 / 82$, de 11 de janeiro, as Casas do Povo são pessoas coletivas de utilidade pública, de base associativa, constituídas por tempo indeterminado com o objetivo de promover o desenvolvimento e o bem-estar das comunidades, especialmente as do meio rural. Incumbe-Ihes, designadamente, o desenvolvimento de atividades de carácter social e cultural, com a participação dos interessados, a colaboração com o Estado e as autarquias, proporcionando-Ihes o apoio que em cada caso se justifique, por forma a contribuírem para a resolução de problemas da população residente nas respetivas áreas. Para a realização dos seus objetivos, deverão as Casas do Povo: a) promover ações de animação sócio-cultural, quer por iniciativa própria, quer de acordo e em coordenação com outras entidades; $b$ ) fomentar a participação das populações nas ações tendentes a satisfazer as necessidades da comunidade da respetiva área e a melhorar a sua qualidade de vida. 
Tendo em conta o enquadramento constitucional do setor da Economia Social em Portugal, a LBES inclui neste elenco as entidades abrangidas pelos subsetores comunitário e autogestionário, integradas nos termos da Constituição da República Portuguesa (CRP) no setor cooperativo e social.

O subsector comunitário abrange "os meios de produção comunitários, possuídos e geridos por comunidades locais" [art. 82. ${ }^{\circ}$, n. $^{\circ} 4$, b) da CRP]. O subsector autogestionário compreende "os meios de produção objeto de exploração coletiva por trabalhadores" [art. 82. ${ }^{\circ}$, n. $^{\circ} 4, \mathrm{c}$ ) da CRP].

Para além destas entidades, que poderemos designar de entidades da Economia Social ex lege, o legislador prevê, na al. h) desta norma, a possibilidade de integrarem o setor da Economia Social outras entidades, desde que preencham três requisitos, a saber: ter personalidade jurídica, respeitar os princípios orientadores da Economia Social e constar da base de dados da Economia Social (esta inclusão na base de dados apresenta-se como um requisito sine qua non).

Sublinhe-se, antes de mais, que neste artigo considera-se que o legislador atuou bem ao partir do pressuposto de que a Economia Social não deve ser definida apenas pelas suas famílias tradicionais (cooperativas, mutualidades, associações e fundações), visto que o setor pode integrar outras organizações, desde que preencham os requisitos acima mencionados. Estas entidades serão, então, entidades da Economia Social "por concessão" e podem assumir a forma jurídica de sociedades comerciais, sempre que respeitem os princípios orientadores previstos na LBES, que serão tratados a seguir (Meira, 2016).

\section{Os princípios orientadores da Economia Social e a ausência de um regime jurídico de suas empresas}

Os princípios orientadores que complementam a delimitação do conceito de Economia Social aparecem enumerados no art. 5. ${ }^{\circ}$ da LBES, nos termos do qual:

[] as entidades da Economia Social são autónomas e atuam no âmbito das suas atividades de acordo com os seguintes princípios orientadores: a) o primado da pessoa e dos objetivos sociais; b) a adesão e participação livre e voluntária; c) o controle democrático dos respetivos órgãos pelos seus membros; d) a conciliação entre o interesse dos membros, utilizadores ou beneficiários e o interesse geral; e) o respeito pelos valores da solidariedade, da igualdade e não discriminação, da coesão social, da justiça e da equidade, da transparência, da responsabilidade individual 


\begin{abstract}
e social partilhada e da subsidiariedade; f ) a gestão autónoma e independente das autoridades públicas e de quaisquer outras entidades exteriores à Economia Social; g) a afetação dos excedentes à prossecução dos fins das entidades da Economia Social de acordo com o interesse geral, sem prejuízo do respeito pela especificidade da distribuição dos excedentes, própria da natureza e do substrato de cada entidade da Economia Social, constitucionalmente consagrada (Diário da República, I série, n. ${ }^{\circ} 88$, de 8 de maio de 2013, p. 2727).
\end{abstract}

Quanto ao elenco dos princípios orientadores, é notória a forte influência dos valores e princípios cooperativos que integram, conjuntamente com a noção de cooperativa, a chamada identidade cooperativa, definida pela Aliança Cooperativa Internacional (ACI), em Manchester, em 1995. Os valores, que funcionam como uma estrutura ética dos princípios cooperativos, são: (i) autoajuda, responsabilidade individual, democracia, igualdade, equidade e solidariedade, os quais assentam a atividade das cooperativas como organizações; (ii) honestidade, transparência, responsabilidade social e altruísmo, que se dirigem ao comportamento individual dos cooperadores enquanto tais.

Por sua vez, os princípios cooperativos são sete: adesão voluntária e livre, gestão democrática pelos membros, participação económica dos membros, autonomia e independência, educação, formação e informação; intercooperação e interesse pela comunidade.

Cumpre, igualmente, destacar a ênfase colocada pela LBES na autonomia destas entidades e na gestão autónoma das mesmas, ainda que o legislador não determine em que consiste esta autonomia nem ofereça critérios para aferir da sua existência.

No presente artigo, considera-se que, quando se afirma que as entidades da Economia Social são autónomas, pretende-se realçar que elas têm uma personalidade jurídica própria e distinta de cada um dos seus membros, isto é, têm uma individualidade jurídica própria traduzida na aptidão para serem titulares autónomos de relações jurídicas. Esta personalidade jurídica implica, necessariamente, a autonomia patrimonial, ou seja, a circunstância de estas entidades terem um património próprio, diferente e independente dos patrimónios dos respetivos membros.

Quanto o legislador fala numa gestão autónoma e independente face às autoridades públicas e outras entidades externas, terá por referência o princípio cooperativo da autonomia e da independência. Assim, esta gestão autónoma e independente assumirá um duplo significado. Por um lado, significará a garantia de que as relações das entidades da Economia Social com o Estado não conduzem à 
sua instrumentalização. O Estado determinará o quadro legislativo que regulará o funcionamento destas entidades e a lei, em concreto, deve definir os benefícios fiscais e financeiros, assim como o estabelecimento de condições privilegiadas em matéria de acesso ao crédito, ao auxílio técnico, entre outras.

Neste sentido, mais adiante, no art. 9. ${ }^{\circ}$ da LBES, consagra-se que o Estado, no seu relacionamento com estas entidades, deve: "estimular e apoiar a criação e a atividade" das mesmas [al. a) do art. 9. ${ }^{\circ}$ da LBES]; "assegurar o princípio da cooperação, considerando, nomeadamente no planeamento e desenvolvimento dos sistemas sociais públicos, a capacidade instalada material, humana e económica das entidades da Economia Social, bem como os seus níveis de competência técnica, e de inserção no tecido económico e social do país" [al. b) do art. 9. ${ }^{\circ}$ da LBES]; e "garantir a necessária estabilidade das relações estabelecidas com as entidades da Economia Social" [al. d) do art. 9. ${ }^{\circ}$ da LBES].

Em suma, o Estado deverá estimular o setor da Economia Social, mas não o poderá tutelar. Por outro lado, esta autonomia visará assegurar que a entrada de capitais de fontes externas não põe em causa, nem a independência nem o controlo democrático destas entidades pelos seus membros; o que assume enorme relevância, dado que muitas entidades da Economia Social necessitam de fundos externos, públicos ou privados, para o desenvolvimento das respetivas atividades.

Refira-se, também, que no presente artigo não se considera adequada a utilização do termo "excedentes" na al. g) desta norma. O legislador deveria ter utilizado o termo "resultados", dado que o termo "excedentes" identifica um específico tipo de resultados caraterístico das cooperativas, não sendo, por isso, suficientemente amplo para abranger as demais entidades.

Efetivamente, o excedente resulta de operações da cooperativa com os seus cooperadores, sendo gerado à custa destes, constituindo "o resultado de uma renúncia tácita dos cooperadores a vantagens cooperativas imediatas". O excedente define-se, assim, como um valor provisoriamente pago a mais pelos cooperadores à cooperativa ou pago a menos pela cooperativa aos cooperadores, como contrapartida da participação destes na atividade da cooperativa. De facto, nas cooperativas pode existir retorno de excedentes, por força do que dispõe o n. 1 do art. $73 .^{\circ}$ do ccoop. Só não será assim para as cooperativas de solidariedade social, nas quais todos os excedentes reverterão obrigatoriamente para reservas (art. $7 .^{\circ}$ do DecretoLei n. ${ }^{\circ} 7 / 98$, de 15 de janeiro), e nas cooperativas de habitação (art. 15. ${ }^{\circ}$ do Decreto-Lei n. ${ }^{\circ}$ 509/99, de 19 de novembro).

O termo "excedentes" significará, portanto, um resultado económico positivo, abrangendo também os lucros. Ao determinar nesta al. g) que tais excedentes (leia-se 
resultados económicos positivos) deverão ser afetados à prossecução dos fins das entidades da Economia Social de acordo com o interesse geral, o legislador estará a admitir a possibilidade da entidade da Economia Social prosseguir um fim lucrativo, impedindo, todavia, a distribuição, e admitindo apenas o retorno do excedente cooperativo. Esta solução legislativa não se compagina, no entanto, com o regime geral previsto para as sociedades comerciais em Portugal, como será apresentado mais adiante.

Finalmente, na esteira do que defende Montesinos Oltra (2012), a propósito da Lei de Bases espanhola, também se entende que as entidades mencionadas nas als. a) a g) do art. $4^{\circ}$ da LBES deverão ser consideradas entidades da Economia Social ex lege, estando subjacente à natureza e ao regime jurídicos destas entidades a observância dos princípios orientadores. Para além destas entidades de Economia Social ex lege, encontram-se na LBES as entidades da Economia Social "por concessão" (possibilidade de outras entidades dotadas de personalidade jurídica e constantes da base de dados da Economia Social virem a integrar este setor), tal como já foi destacado. Ora, relativamente a estas, o legislador refere expressamente, na al. h) do art. 4. ${ }^{\circ}$, à necessidade de as mesmas observarem os princípios orientadores da Economia Social (Meira, 2016).

Neste contexto, e ainda que a LBES não se refira nominalmente à empresa social nem à sociedade comercial, certa doutrina considera que as sociedades comerciais não estão excluídas à partida do setor da Economia Social ao abrigo da referida al h) do art. 4. (Farinho, 2015). Tudo isto sem prejuízo de serem identificáveis algumas dificuldades por parte das sociedades comerciais na observância destes princípios orientadores, como será exposto mais adiante.

\section{As sociedades como entidades lucrativas}

Segundo o art. $980^{\circ}$ do Código Civil português (daqui em diante, ccıv), o "contrato de sociedade é aquele em que duas ou mais pessoas se obrigam a contribuir com bens e serviços para o exercício em comum de certa atividade económica, que não seja de mera fruição, a fim de repartirem os lucros resultantes dessa atividade". 0 que o ccıv oferece é a "noção" de contrato de sociedade e não a noção de sociedade (Ramos, 2018).

O Código das Sociedades Comerciais português (daqui em diante, csc) não define nem caracteriza sociedade. O capítulo III do csc intitula-se "contrato de sociedade", mas não oferece em momento algum a caracterização do contrato de sociedade. Perante este silêncio, um dos caminhos que tem sido trilhado pela doutrina 
portuguesa é o de convocar o art. 980 ${ }^{\circ}$ do ccıv. Desta norma podem ser retirados os seguintes elementos caracterizadores do contrato de sociedade: a) intervenção de duas ou mais pessoas como partes do negócio; b) que se obrigam a contribuir com bens ou serviços; c) com o propósito de exercerem em conjunto uma certa atividade que não seja de mera fruição; d) e de obterem lucro destinado a ser distribuído pelos sócios; e) estando todos os sócios sujeitos a perdas.

É possível identificar a noção genérica de sociedade (diz-se genérica porque vale para os diversos tipos societários) que, sem ignorar o contributo do art. $980{ }^{\circ}$ do ccIv, pondere outros dados do sistema jurídico. A sociedade como ato jurídico apresenta as seguintes notas características: uma ou várias pessoas que se obriga(m) a contribuir com bens ou serviços para o exercício de uma determinada atividade económica, com vista, em regra, à obtenção de lucros, e sujeitando-se às perdas (Ramos, 2017).

À luz da ordem jurídica portuguesa é possível identificar a noção genérica de sociedade-entidade: "Sociedade é a entidade que, composta por um ou mais sujeitos (sócios), tem um património autónomo para o exercício de atividade económica, a fim de (em regra) obter lucros e atribuí-los ao(s) sócio(s) -ficando este(s), todavia, sujeito(s) a perdas" (Abreu, 2017, p. 44).

A sociedade tem sempre um substrato pessoal: em determinadas situações previstas na lei são admitidas sociedades constituídas por um único sócio, as designadas sociedades unipessoais. O sócio pode, em regra, ser pessoa singular ou coletiva.

A sociedade tem um património autónomo que está destinado ao exercício da atividade económica. Efetivamente, a sociedade dispõe de um fundo patrimonial destinado a ser afetado ao exercício da atividade económica. No início da sociedade, tal fundo é constituído pelos direitos correspondentes à obrigação de cada um dos sócios de contribuir com bens ou serviços para a sociedade [art. 20. ${ }^{\circ}$ a)]. Trata-se da obrigação de entrada.

O objeto da sociedade designa a atividade económica que o(s) sócio(s) decidem que a sociedade exerça. Dado que as sociedades destinam-se a exercer uma "atividade económica", elas não estão vocacionadas para a prática de um negócio jurídico episódico ou singular. A atividade supõe sucessão na prática de atos, reiteração.

Por outro lado, a atividade económica exercida em comum não pode ser de "mera fruição". Quer-se com este requisito significar que a atividade económica eleita como objeto de sociedade não pode consistir na mera percepção dos frutos, sejam eles frutos civis ou frutos naturais.

Resulta do art. 980. do ccıv que a atividade económica será exercida "em comum". Este requisito deve ser entendido habilmente. Na verdade, não há exercício 
em comum nas sociedades unipessoais. Acresce que nas sociedades dotadas de personalidade jurídica, em rigor, a atividade é exercida pela sociedade e não pelos sócios. Como será estudado mais tarde, o "exercício em comum" cumpre-se quando os sócios podem participar direta ou indiretamente (nomeadamente através da designação de titulares de órgãos sociais) na condução dos destinos da sociedade (Xavier, 1987).

Por fim, a sociedade tem fim lucrativo. Há que distinguir, a este propósito o lucro subjetivo do lucro objetivo. O lucro é "um ganho traduzível num incremento do património da sociedade" (Abreu, 2017). A sociedade destina-se a conseguir este incremento no património da sociedade (lucro objetivo), mas não se basta com este resultado. É necessário que tal incremento seja repartido entre os sócios (o lucro subjetivo). Pode acontecer que os lucros só sejam distribuídos durante a vida da sociedade (lucros periódicos) ou no momento da liquidação desta (lucros finais).

Os sócios estão sujeitos a perdas, o que significa que os sócios podem não recuperar o que investiram a título de entrada para a sociedade e de outras prestações com que tenham contribuído. Embora a sujeição a perdas não conste do art. $9800^{\circ}$ do CCIV, ela resulta quer do art. $994 .^{\circ}$ do ccIV quer do art. $22 .{ }^{\circ}, 3$, do CSC.

\section{As sociedades, responsabilidade social e empresas sociais}

Do vasto debate em torno das empresas sociais, há dois problemas jurídicos que se salientam: a) a forma jurídica e b) o escopo lucrativo ou não das empresas sociais. Sublinha a Comissão Europeia que não há uma única forma jurídica para as empresas sociais. Teoricamente falando (e sem considerar nenhuma ordem jurídica em particular), é possível identificar: a) empresas com fins lucrativos que incorporam na sua organização uma vertente de missão social, em particular, através das políticas de responsabilidade social (por exemplo, uma sociedade de distribuição que mantém um programa de bolsas de estudo para os seus trabalhadores); b) organizações sem fins lucrativos que exploram empresas (cooperativas, mutualidades, fundações que são titulares de empresas) e c) figuras legais híbridas (Ramos, 2018).

Considera-se neste artigo que a circunstância de uma determinada sociedade adotar políticas de autofınanciamento e não distribuir os lucros não a torna uma organização não lucrativa. O que acontece é que, no momento da dissolução e liquidação da sociedade, os lucros finais são necessariamente distribuídos pelos sócios.

Tal como já foi referido, alguns países consagraram figuras legais específicas para acomodar as empresas sociais e as suas singularidades. Abreu (2015) ensaia a seguinte definição de empresa social: "é empresa social a entidade sem fins lucrativos 
que desenvolve de modo autónomo (sem dependência em relação a entidades privadas ou públicas) uma atividade assente normalmente em organização de meios com identidade própria (cindível da entidade)" (p. 372). Nesta definição de empresas sociais entram as empresas do setor cooperativo e social (art. 82. ${ }^{\circ}, 4$, da CPR) e as entidades da Economia Social elencadas no art. 4. ${ }^{\circ}$ da Lei de Bases da Economia Social.

Acrescenta Abreu (2015), em ordem a melhor precisar o sentido de empresa social, em primeira linha, o sentido subjetivo. No entanto, "a empresa-entidade utilizará como instrumento, em regra, uma empresa em sentido objetivo, exercerá atividade suportada em 'organização de meios' ou estrutura produtivo-económica objeto de direitos e de relações jurídicas" (pp. 372-373). "Não parece merecer a qualificação de 'empresa' (ainda que 'social'), por exemplo, uma associação de apoio a doentes hospitalizados que exerce a sua atividade (puramente altruística ou de solidariedade social) utilizando tão só os serviços gratuitos (o "dom") dos associados" (Abreu, 2015, p. 373).

Em Portugal, a questão de saber se as sociedades comerciais podem ser consideradas empresas sociais suscita-se porque, de acordo com a definição genericamente aceite de sociedade, esta visa a obtenção de lucros destinados a serem distribuídos pelos sócios (art. 980. ${ }^{\circ}$ do ccıv). Acresce que as sociedades não respeitam necessariamente a organização democrática [art. 5. ․ c), da LBES], nem vigora, em regra, o princípio da porta aberta.

Efetivamente, o princípio do controlo democrático pelos seus membros não se aplicará às sociedades comerciais que revestem a forma de sociedade por quotas ou anónima. Nestas, será o capital -e não as condições pessoais dos sócios- o que determinará e organizará todo o complexo de direitos e obrigações dos mesmos, com particular destaque para o direito de voto que, em princípio, será proporcional ao valor da participação do sócio no capital social. Saliente-se, ainda, o desrespeito pelo princípio da adesão livre e voluntária que no caso das cooperativas corresponderá ao princípio cooperativo da adesão voluntária e livre, o qual confere à cooperativa uma variabilidade estrutural, quer no plano dos cooperadores, quer no plano do capital social (n. ${ }^{\circ} 1$ do art. 2..$^{\circ}$ e n. ${ }^{\circ} 1$ do art. 81. ${ }^{\circ}$, ambos do ccoop) (Meira, 2009). Ora, o capital social de uma sociedade comercial convencional é, em regra, fixo e estável, apenas podendo ser alterado na observância do processo rigoroso previsto para a modificação do contrato de sociedade (Domingues, 2009).

Por outro lado, os lucros obtidos destinam-se a ser apropriados pelos sócios (seja na forma de lucros periódicos, seja enquanto lucros finais). Por isso, Abreu (2015) considera que, no atual quadro legislativo português, as sociedades não podem ser reconhecidas como empresas sociais. 
É diferente a opinião de Farinho (2015) que considera que a Lei de Bases da Economia Social não exclui as sociedades do setor da Economia Social, e que o art. $4 .^{\circ}$, al. h) desta lei abre caminho a que as empresas sociais possam assumir forma societária em Portugal. Deve questionar-se, todavia, se as sociedades que adotam políticas de responsabilidade social (RSE) podem ou não ser consideradas empresas sociais.

A internacionalização da responsabilidade social das empresas é o resultado quer da reflexão levada a cabo por várias instâncias internacionais (Nações Unidas; OCDE, União Europeia e outras organizações), quer das práticas adotadas por empresas com atividade transnacional (Guilarte, 2006; Serra, 2009). A Comissão considera que "a principal função de uma empresa consiste em criar valor através da produção de bens e serviços (...) gerando assim lucros para os seus proprietários e accionistas" e que "apenas as empresas lucrativas são sustentáveis e apresentam melhores hipóteses de adotar/desenvolver práticas responsáveis".

Em 2001, a Comissão Europeia publicou um livro verde intitulado Promover um quadro europeu para a responsabilidade social das empresas (RSE) e definiu a RSE como "a integração voluntária de preocupações sociais e ambientais por parte das empresas nas suas operações e na sua interação com outras partes interessadas"

Na ordem jurídica portuguesa, o art. $64 .{ }^{\circ}, 1$, b) do CSC, relativo ao dever de lealdade dos administradores de sociedades, foi permeável à influência da "responsabilidade social das empresas" (Ramos, 2012, p. 132).

As empresas socialmente responsáveis valorizam interesses de não sócios e a eles dedicam parte da sua atividade e dos resultados (Guilarte, 2006). São muito variadas as iniciativas aptas a servir este propósito, por exemplo, escolha de fornecedores socialmente responsáveis; colaboração em campanhas de angariação de alimentos; adoção de medidas que permitam conciliar a vida familiar com o trabalho na empresa; promoção de maior qualificação dos funcionários; uso sustentável de energia; filantropia e mecenato; transporte coletivo dos empregados; financiamento da aprendizagem de trabalhadores e seus familiares; estruturação de planos de carreira a longo prazo; participar na Bolsa de Valores Sociais (Castro, 2009; Meira, 2012; Serens, 2014), entre outros.

9 Comissão das Comunidades Europeias, Livro Verde - Promover um quadro europeu para a responsabilidade social das empresas, сом (2001) 366 final, 18.7.2001; Comissão das Comunidades Europeias, Comunicação da Comissão relativa à responsabilidade social das empresas: um contributo das empresas para o desenvolvimento sustentável, com (2002) 347 final, 2.7.2002. 
Atualmente, fala-se também de "cidadania empresarial", querendo-se referir ao compromisso da empresa com a sociedade, atuando de acordo com o modelo do "bom cidadão". Também é preciso nomear os dez princípios do Pacto Global das Nações Unidas.

O pacto pede às empresas que adiram a dez princípios universais em matéria de direitos humanos, de normas laboraise de ambiente. Associa as empresas a organizações da onU, a organizações laborais internacionais, ONG e outras partes, para promover parcerias e criar um mercado global mais equitativo e suscetivel de favorecer a inclusão. (Pacto Global, p. 1)

No entanto, não se deve esquecer que nem todas as sociedades são democráticas, algumas são de matriz essencialmente plutocrática. Em particular, nas sociedades anónimas, não releva tanto a pessoa ou as qualidades pessoais do acionista, mas sim o seu contributo financeiro para a sociedade. Este tipo societário admite acionistas sem direito de voto, procura a maximização do lucro, propicia a separação entre propriedade e gestão. Neste contexto, a responsabilidade social é tão só circunstancial.

De modo radicalmente diverso, nas empresas sociais, a responsabilidade social faz parte da sua matriz, não é uma opção ou um instrumento de marketing, faz parte do seu modo de ser, e não é um "modo de ter" mais clientes ou mais reputação (Henrÿ, 2013).

Certamente, é vantajoso que as empresas capitalistas incrementem medidas de responsabilidade social, tendo em conta que elas poderão produzir efeitos benéficos no universo onde se situa a empresa. Especialmente num momento histórico em que o Estado recua na proteção dos menos favorecidos. Lembra Henrÿ (2013):

La situación social global presenta dos aspectos: el material, de la pobreza; y el inmaterial, de desequilibrio social, es decir, de (in)justicia social. Me parece que un factor de la debilidad del Estado del bienestar es que se ha transformado en un Estado de "asistencia social" cuya eficacia es función de sus recursos financieros/materiales. (p. 3)

No entanto, a natureza das sociedades anónimas é "individual-egoística". A adoção de medidas de responsabilidade social da empresa não altera a natureza intrínseca das capitalistas sociedades anónimas (Ramos, 2015). 
Ripert escreveu nos anos quarenta do século passado: "La société anonyme est un merveilleux instrument créé par le capitalisme moderne pour collecter l'épargne en vue de la fondation et de l'exploitation des entreprises" (Ripert, 1946, p. 51). A propósito destas sociedades de capitais, Ripert acrescentou: "que sont les actionnaires dans la vie mécanique de cet être prodigieux? Rien du tout" (Ripert, 1946, p. 52). Por conseguinte, neste artigo considera-se que uma sociedade dotada de responsabilidade social não se transforma imediata e irremediavelmente em empresa social.

\section{Empresas sociais em Portugal - regime jurídico em construção}

O primeiro regime jurídico nominalmente designado de empresa social em Portugal corresponde ao regime das empresas sociais de inserção, que se integram numa tradição europeia de empresas sociais destinadas a assegurar a integração dos desempregados de longa duração e outros tipos de desempregados com caraterísticas específicas, tal como já foi referido.

Nos termos da Resolução do Conselho de Ministros n. ${ }^{\circ}$ 49/2008, de 6 de março, as empresas de inserção, reguladas pela Portaria n. ${ }^{\circ}$ 348-A/1998, de 18 de junho [entretanto revogada pela al. m) do art. 25. ${ }^{\circ}$ do Decreto-Lei n. ${ }^{\circ}$ 13/2015], são consideradas empresas sociais. A referida Portaria define, no n. 1 do seu art. $3^{\circ}{ }^{\circ}$, as empresas de inserção como pessoas coletivas sem fins lucrativos que tenham por fim a reinserção socioprofissional de desempregados de longa duração ou em situação de desfavorecimento face ao mercado de trabalho. Podem revestir nomeadamente as seguintes formas: cooperativa, associação, fundação e instituição particular de solidariedade social. Devem, ainda, funcionar segundo "modelos de gestão empresarial" (n. ${ }^{\circ} 1$ do art. $5 .^{\circ}$ da Portaria). Daqui resulta que o legislador restringe as empresas de inserção às entidades sem fins lucrativos.

Também no Projeto de Lei n. ${ }^{0}$ 68/XII, de 16 de setembro de $2011^{10}$, apresentado pelos Grupos Parlamentares do PSD e CDS-PP ${ }^{11}$, encontrou-se uma referência expressa às empresas sociais. Assim, na al. c) do n. ${ }^{\circ} 2$ do art. $13 .{ }^{\circ}$ do referido projeto, dispõe-se que a reforma legislativa do setor da Economia Social envolverá também "a criação do regime jurídico das empresas sociais, enquanto entidades que desenvolvem uma atividade comercial com fins primordialmente sociais, e cujos excedentes são, no essencial, mobilizados para o desenvolvimento daqueles fins ou reinvestidos

10 DAR II série A N. ${ }^{\circ}$ 31/XII/1 2011.09.19 (pp. 24-29).

11 O texto do projeto pode ser consultado em https://www.parlamento.pt/ ActividadeParlamentar/Paginas/Detalhelniciativa. aspx?BID=36468. 
na Comunidade". Todavia, após discussão na generalidade, esta norma seria eliminada do texto final do projeto.

Finalmente, encontramos uma definição de empresa social no n. 7 do art. 250. ${ }^{\circ}$-D do Código dos Contratos Públicos"12. Este artigo, que versa sobre os "contratos reservados para determinados serviços", nomeadamente serviços de saúde, sociais, de ensino e culturais que se encontrem incluídos no anexo $x$ do Código n. ${ }^{0} 1$, dispõe, no seu n. ${ }^{\circ}$, que o regime nele consagrado é, ainda, aplicável às empresas sociais, constituídas nos termos legalmente previstos, desde que se encontrem cumpridos cumulativamente os requisitos enunciados no n. ${ }^{0} 2$, a saber:

a) terem por objeto a prossecução de uma missão de serviço público ligada à prestação dos serviços a que se refere o número anterior; b) reinvestirem os seus lucros com vista à consecução do objetivo da organização ou, caso sejam distribuídos ou redistribuídos, fazê-lo com base em considerações de natureza participativa; c) contarem com a participação dos trabalhadores no capital social da organização que executa o contrato ou basearem a sua estrutura de gestão em princípios participativos que requerem o envolvimento ativo dos trabalhadores, utilizadores ou partes interessadas; d) não terem celebrado nos últimos três anos, com a mesma entidade adjudicante, qualquer contrato abrangido pela presente secção (Aditado pelo/a Artigo 5. ${ }^{\circ}$ do/a Decreto-Lei n. 111-B/2017 - Diário da República n. ${ }^{\circ}$ 168/2017, $2^{\circ}$ Suplemento, Série I de 2017-08-31, em vigor a partir de 2018-01-01).

Consideram-se completados estes requisitos quando as organizações sejam constituídas ou participadas, nos termos legalmente admitidos, por entidades que preencham, individualmente ou em conjunto, os referidos requisitos ( $n .^{\circ} 5$ ). Finalmente, o n. ${ }^{\circ}$ estabelece que:

[] para efeitos do disposto no presente artigo, são consideradas empresas sociais aquelas que se dedicam à produção de bens e serviços com forte componente de empreendedorismo social ou de inovação social, e promovendo a integração no mercado de trabalho, através do desenvolvimento de programas de investigação, inovação e desenvolvimento

12 Decreto-Lei n. ${ }^{\circ}$ 18/2008, de 29 de janeiro, alterado e republicado pelo Decreto-Lei n. ${ }^{\circ} 111$ $B / 2017$, de 31 de agosto (retificado pelas declarações de retificação n. ${ }^{0} 36-A / 2017$, de 30 de outubro e n. ${ }^{\circ} 42 / 2017$, de 30 de novembro). 
social, nas áreas dos serviços previstos no n. 1 (Aditado pelo/a Artigo 5. ${ }^{\circ}$ do/a Decreto-Lei n. ${ }^{\circ} 111-B / 2017$ - Diário da República n. ${ }^{\circ}$ 168/2017, $2^{\circ}$ Suplemento, Série I de 2017-08-31, em vigor a partir de 2018-01-01).

Esta é, até ao presente, a única noção jurídica de empresa social em Portugal, ainda que se trate de uma definição setorial. De destacar que nela não se impede a prossecução do lucro, revelando, deste modo, um entendimento da empresa social que abrangerá quer as entidades sem fins lucrativos, quer as entidades lucrativas, como é o caso das sociedades comerciais.

\section{Conclusões}

A LBES não prevê expressa e imediatamente o conceito de empresa social. O teor literal do art. $4 .^{\circ}$, al. h, da LBES não é claro nem na aceitação da sociedade comercial como empresa social nem na rejeição de tal entendimento. Vive-se, atualmente, no quadro jurídico português, uma situação de dúvida sobre esta questão legal.

Na ordem jurídica portuguesa, a relação entre as empresas sociais e as sociedades é tensa. Os princípios orientadores da Economia Social valorizam a não lucratividade, mas não parecem afastar a possibilidade de entidades lucrativas integrarem o setor da Economia Social.

No presente artigo, considera-se que não é só o escopo lucrativo que separa as sociedades das empresas sociais, mas também a falta de democraticidade de alguns tipos societários (máxime a sociedade anónima), a irrelevância da pessoa do sócio, o intuito egoístico das sociedades e, não menos importante, o caráter circunstancial e voluntário das políticas de responsabilidade social.

É controverso que, na ausência de normas específicas, seja possível proibir a distribuição de lucros nas sociedades comerciais à luz do ordenamento português. Para resolver esta controvérsia, outros ordenamentos jurídicos têm adotado legalmente modelos organizacionais híbridos cujo regime jurídico proíbe a distribuição de lucros.

Não existe no ordenamento português uma definição genérica de empresa social. A ordem jurídica portuguesa contempla uma definição de empresa social no art. 250. ${ }^{\circ}-\mathrm{D}, \mathrm{n} .{ }^{\circ}$ 7, do Código dos Contratos Públicos. Todavia, trata-se de uma definição setorial, com efeitos circunscritos ao universo do regime da contratação pública. A esta caraterização de empresa social não pode ser atribuído o alcance de uma definição genérica e válida para todo o sistema jurídico português.

Apesar dos esforços e das iniciativas das instituições da União Europeia, máxime, da Comissão Europeia e do Parlamento Europeu, até ao momento não existe 
harmonização de regimes de Economia Social ou de empresa social. No entanto, destas iniciativas já é possível retirar a conclusão de que, no entendimento das instituições da União Europeia, as sociedades podem, cumpridos determinados requisitos, ser consideradas empresas sociais.

Embora muito relevante, este entendimento que se vai sedimentando nas iniciativas da União Europeia não é vinculativo para aos Estados-membros, tendo em conta que a Comissão se tem servido de instrumentos de soft law (por exemplo, comunicações) para expressar o seu entendimento em torno de matérias relativas à Economia Social e às empresas sociais. Vários Estados-membros, conscientes das dificuldades em acomodar as empresas sociais no regime geral das sociedades, criaram figuras híbridas.

Considera-se que, face às posições doutrinais já existentes e a legislação em vigor em diversos ordenamentos jurídicos, a empresa social pode ser entendida como uma entidade de natureza privada e independente do Estado ou outra entidade pública, que prossegue uma atividade de interesse geral, é gerida de forma empresarial, não tem fim lucrativo ou os lucros são principalmente reinvestidos no escopo prosseguido, e está assente num modo de organização baseado nos princípios democrático e participativo.

Deste modo, conclui-se que as empresas sociais não são necessariamente organizações sem fins lucrativos, e podem, pelo contrário, ter fins lucrativos. Esta posição não é contrariada pelas tendências do direito da união europeia. Atualmente, a empresa social é um conceito não harmonizado que tem sido tratado essencialmente através de instrumento de soft law, tal como ficou evidenciado neste estudo.

\section{Referências}

Abreu, J. M. C. (2015). Curso de direito comercial - Das sociedades. Coimbra: Almedina.

Abreu, J. M. C. (2015). Empresas sociais (nótulas de identificação). Cooperativismo e Economia Social 37, pp. 369-376.

Abreu, J. M. C. (2017). Artigo 1. ․ Em J. M. Coutinho de Abreu (ed.), Código das Sociedades Comerciais em comentário, Vol. I, $2^{\text {a }}$ ed. (pp. 38-59), Coimbra: Almedina.

Almeida, V. (2011). As Instituições Particulares de Solidariedade Social. Coimbra: Almedina/CES. 
Borzaga, C.; Galera, G. e Nogales, R. (2008). Social enterprise: a new model for poverty reduction and employment generation. Bratislava: UNDP-Regional Bureau For Europe and the Commonwealth of Independent States.

Castro, J. A. D. (2009). Buen gobierno. Organización empresarial y responsabilidad social. En Gobierno corporativo y responsabilidad social de las empresas, pp. 79-80, Madrid: Marcial Pons.

Código Civil Português - aprovado pelo Decreto-Lei n. ${ }^{\circ} 47344$ - Diário do Governo n. ${ }^{\circ}$ 274/1966, Série I de 25 de novembro de 1966.

Código das Sociedades Comerciais - aprovado pelo Decreto-Lei n. ${ }^{\circ}$ 262/86, de 2 de setembro.

Comité Económico e Social Europeu (2016). Parecer exploratório do CESE sobre o tema "Construir um ecossistema financeiro para as empresas sociais” (2016/C 013/23) (JO C 13 de 15.1.2016).

Comité Económico e Social Europeu (2017). Evolução recente da economia social na União Europeia. Bruxelas: Síntese.

Comissão Europeia (2016). O futuro das empresas sociais e da economia social. Um apelo à ação do Grupo de Peritos da Comissão sobre o Empreendedorismo Social (GECES). Síntese e Recomendações. Bruxelas.

Comunicação da Comissão ao Parlamento Europeu, ao Conselho, ao Comité Económico e Social Europeu e ao Comité das Regiões. Iniciativa de Empreendedorismo Social. Construir um ecossistema para promover as empresas sociais no centro da economia e da inovação sociais, SEC (2011) 1278 final.

Constituição da República Portuguesa - aprovada pelo Decreto de 10 de abril de 1976.

Decreto-Lei n. ${ }^{\circ}$ 119/83, de 25 de fevereiro, republicado pelo Decreto-Lei n. ${ }^{\circ}$ 172-A/2014, de 14 de novembro, alterado pela Lei n. ${ }^{\circ} 76 / 2015$, de 28 de julho,) (Almeida, 2011) - Estatuto das IPSS.

Decreto-Lei n. ${ }^{\circ}$ 78/98, de 15 de janeiro - Regime jurídico das Cooperativas de solidariedade social.

Decreto-Lei n. ${ }^{\circ}$ 18/2008, de 29 de janeiro, alterado e republicado pelo Decreto-Lei n. ${ }^{\circ}$ 111-B/2017, de 31 de agosto (retificado pelas declarações de retificação n. ${ }^{\circ}$ 36-A/2017, de 30 de outubro e n. ${ }^{\circ}$ 42/2017, de 30 de novembro) - Código dos contratos públicos.

Defourny, J. e Nyssens, M. (2012). El enfoque EmES de la empresa social desde una perspectiva comparada. cIRIEC-España, Revista de Economía Pública, Social y Cooperativa, 75, pp. 7-34. 
Domingues, P. T. (2009). Variações sobre o capital social, Coimbra: Almedina.

Fajardo, G.; Fici, A.; Henrÿ, H.; Hiez, D.; Münkner; H. e Snaith, I. (2013). El nuevo grupo de estudio en Derecho Cooperativo Europeo y el proyecto "Los Principios del Derecho Cooperativo Europeo". Revista Jurídica de Economía Social y Cooperativa, 24, pp. 331-350.

Fajardo, G.; Fici, A.; Henrÿ, H.; Hiez, D.; Meira, D.; Münkner, H-H. e Snaith, I. (2017). Principles of European Cooperative Law. Principles, Commentaries and National Reports. Cambridge: Intersentia.

Farinho, D. (2015). A sociedade comercial como empresa social - breve ensaio prospetivo a partir do direito societário português. Revista de Direito das Sociedades, 7 (2), pp. 247-270.

Fici, A. (2016). Funzione e modelli de disciplina dell'impresa sociale in prospetiva comparata. Em Verso un Diritto Dell'Economia Sociale. Teoria. Tendenze e Prospettive Italiane ed Europee, pp. 289-340. Napoli: Editoriale Scienttifica.

Fici, A. (2017). The social enterprise in the cooperative form. Cooperativismo e Economía Social, 39, pp. 35-53.

Guilarte, J. S.-C. (2006). Creación de valor, interés social y responsabilidad social corporativa. En Derecho de sociedades anónimas cotizadas, pp. 851-913, Cizur Menor: Aranzadi.

Henrÿ, H. (2013). Superar la crisis del estado de bienestar: el rol de las empresas democráticas, una perspectiva jurídica. CIRIEC-España. Revista Jurídica, 24, pp. 11-20.

Lei n. $30 / 2013$, de 8 de maio - Lei de Bases da Economia Social (LBES).

Lei n. ${ }^{\circ}$ 119/2015, de 31 de agosto, com as alterações constantes da Lei n. ${ }^{\circ}$ 66/2017, de 9 de agostoCódigo Cooperativo Português.

Meira, D. M. (2009). O regime económico das cooperativas no direito português: o capital social. Porto: Vida Económica.

Meira, D. A. (2012). Iniciativas pioneiras en torno a la responsabilidad social corporativa: la Bolsa de Valores Sociales en Portugal. En Empresa responsable y crecimiento sostenible: aspectos conceptuales societarios y financieros, pp. 291-308. Thomson Reuters Aranzadi.

Meira, D. A. (2016). La legge portoghese sull' economia sociale. Em Fici, A. (Ed), Verso un Diritto Dell' Economia Sociale. Teoria. Tendenze e Prospettive Italiane ed Europee (pp. 179-204). Napoli: Editoriale Scienttifica. 
Montesinos O. S. (2012). Ley de Economía Social, interés general y regímenes tributários especiales. cIRIEC-España, Revista Jurídica de Economía Social y Cooperativa, 23, pp. 13-19.

Murray, H. (2015). Corporate Forms of Social Enterprise: Comparing the State Statutes. Disponível em: www.ssrn.com.

Namorado, R. (2007). Renovar os quadros jurídicos da Economia Social? Oficina do Centro de Estudos Sociais, 293.

Organização das Nações Unidas (2010). Dez Princípios do Pacto Global das Nações Unidas. https://www.unglobalcompact.org/what-is-gc/mission/principles

Parlamento Europeu (2016). Projeto de relatório que contém recomendações à Comissão sobre um estatuto para as empresas sociais e solidárias (2016/2237 INL), 23 de outubro de 2017. http:// www.europarl.europa.eu/sides/getDoc.do?pubRef=-//EP//TEXT+COMPARL+PE-612.248+ $01+\mathrm{NOT}+\mathrm{XML}+\mathrm{V} 0 / / \mathrm{PT}$

Ramos, M. E. (2012). Responsabilidad social corporativa en el contexto del buen gobierno. Interés social y comportamiento del órgano de administración. Especial atención al caso português. En Ángel Fernández-Albor Baltar (Ed.), Empresa responsable y crecimiento sostenible: aspectos conceptuales, societarios y financieros (pp.117-135), Navarra: Thomson Reuters Aranzadi.

Ramos, M. E. (2015). Gestão democrática das cooperativas - que desafios?. Em J. Carlos Loureiro/ Suzana Tavares Silva, Economia social e civil: estudos Vol. I (pp. 105-170), Coimbra: Instituto Jurídico.

Ramos, M. E. (2017). Artigo 7.‥ Em J. M. Coutinho de Abreu (Ed.), Código das Sociedades Comerciais em comentário, Vol. I, $2^{\mathrm{a}}$ ed. (pp. 127-150), Coimbra: Almedina.

Ramos, M. E. (2018). Direito comercial e das sociedades - Entre as empresas e o mercado. Coimbra: Almedina.

Regulamento (CE) n. ${ }^{\circ}$ 435/2003, do Conselho, de 22 de Julho de 2003 - Estatuto da Sociedade Cooperativa Europeia (ESCE).

Ripert, G. (1946). Aspects juridiques du capitalisme moderne. Paris: Librairie Générale de Droit et Jurisprudence.

Serens, M. N. (2014). “Corporate sponsored foundations: altruísmo ou (ainda) economicidade?”. In III Congresso Direito das Sociedades em Revista (pp. 585-605), Coimbra: Almedina. 
Serra, C. (2009). "A responsabilidade social das empresas - sinais de um instituto jurídico iminente?". Em Diogo Leite de Campos (ed.). Estudos em Homenagem ao Prof. Doutor Manuel Henrique Mesquita (pp. 835-867), Vol. II, Coimbra: Coimbra Editora.

Xavier, L. V. (1987). Sociedades comerciais (Lições aos alunos de Direito comercial do $4^{\circ}$ ano jurídico). Coimbra. 